\title{
Medical or endovascular management of acute type B aortic dissection
}

\author{
Jonathan C. Hong, MD, ${ }^{a}$ Alice Le Huu, MD, ${ }^{a}$ and Ourania Preventza, MD ${ }^{\mathrm{a}, \mathrm{b}}$
}

Feature Editor's Introduction-The approach to acute aortic syndromes is evolving rapidly as endovascular therapies are refined and hybrid approaches with open surgical techniques and combinations of endovascular therapy with optimal medical management are being investigated. This is changing the potential landscape of treatment of aortic dissection. The perioperative care of these patients is being transformed accordingly, and the concept of aortic centers is solidifying to better care for complex aortic disease. Of the different classifications of aortic dissection, the most widely used is the Stanford Classification, in which type A aortic dissection and type $B$ aortic dissection (TABD) are defined based on the origin of the intimal tear proximal or distal to the left subclavian artery, respectively. Traditionally, this classification system has been successful due to the easy recognition and practical therapeutic approach. Where acute type A aortic dissection is typically a surgical emergency, the traditional management of TBAD is primarily medical management where pain control and blood pressure control with an emphasis on anti-impulse therapy are the cornerstones of treatment given the high morbidity and mortality associated with open surgery. Notwithstanding, in parallel to the growth of endovascular therapies, there has been increased study on the benefits of endovascular approaches to TBAD, increasing the options to manage this aortic syndrome.

In this important Invited Expert Opinion article, Preventza and colleagues discuss the advances and controversies in the evolving approach to TBAD. The authors start by describing the deficiencies of the current classification system and the new classifications being developed to address them. As important as the anatomic classification is the crucial role of time and the authors describe the updated definitions regarding timing of aortic dissection from hyperacute ( $<24$ hours) to chronic ( $>90$ days) and how this facilitates decision making regarding use of endovascular techniques as the characteristics of the dissection flap change with time. An essential section on TBAD

From the a Division of Cardiothoracic Surgery, Michael E. DeBakey Department of Surgery, Baylor College of Medicine, Houston, Tex; and ${ }^{\mathrm{b}}$ Department of Cardiovascular Surgery, Texas Heart Institute, Houston, Tex.

Received for publication Dec 18, 2020; revisions received March 17, 2021; accepted for publication March 17, 2021; available ahead of print April 27, 2021.

Address for reprints: Ourania Preventza, MD, Division of Cardiothoracic Surgery, Michael E. DeBakey Department of Surgery, Baylor College of Medicine, One Baylor Plaza, BCM 390, Houston, TX 77030 (E-mail: preventz@bcm.edu).

J Thorac Cardiovasc Surg 2022;164:1058-65 $0022-5223 / \$ 36.00$

Copyright $₫ 2021$ Published by Elsevier Inc. on behalf of The American Association for Thoracic Surgery

https://doi.org/10.1016/j.jtcvs.2021.03.127

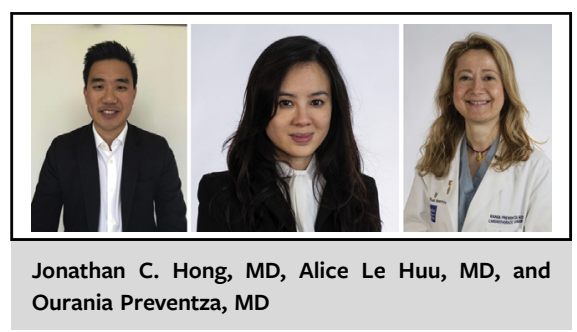

CENTRAL MESSAGE

For acute TBAD with rupture and malperfusion, TEVAR is the first-line treatment. Increasing evidence shows that TEVAR is beneficial for patients with high-risk clinical or radiographic features.

See Commentaries on pages 1066 and 1067.

complications and high-risk features is included, and the authors also review the evidence on the endovascular approach to TBAD, including strategies and indications, timing, and different trials to date. They also cover intraoperative adjuncts, such as use of intravascular ultrasound and spinal fluid drainage. Finally, they describe their approach to $T A B D$, including intraoperative and postoperative tips.

This article is timely because it describes how TBAD is not just a medical emergency. Endovascular approaches could complement optimal medical therapy in addition to providing guidance on what constitutes a high-risk TBAD and what to consider when managing these patients at established aortic centers.

\section{Juan N. Pulido, MD}

The optimal management of acute type B aortic dissection (TBAD) remains to be determined. Traditionally, this clinical entity has been managed medically because of the high risk of morbidity and mortality that was associated with open surgery. Acute TBAD is a complex disease that can have a variety of presentations. Thus, the terms complicated and uncomplicated aortic dissection, which are often used in the literature, are misleading given the natural history, presentations, and complications of the disease. High-risk 
characteristics often preclude favorable outcomes when treatment consists solely of medical management.

In recent years, new endovascular approaches have been developed to address TBAD. These new approaches supplement medical management and are essential to achieving successful outcomes for patients with complicated TBAD.

\section{TRADITIONAL CLASSIFICATION AND NEW PROPOSED CLASSIFICATION SYSTEMS FOR AORTIC DISSECTION \\ Anatomic Classification}

In the Stanford classification, which is the most widely used system because of its simplicity, TBAD is defined by an intimal tear originating distal to the left subclavian artery. ${ }^{1}$ According to the DeBakey classification, ${ }^{2}$ distal dissections are characterized by the origin of the intimal tear and the extent of the dissection. The type III aortic dissection is divided into 2 subtypes: type IIIA (limited to the descending thoracic aorta) and type IIIB (extension below the diaphragm). Neither the Stanford and nor the DeBakey classification addresses dissections originating within the aortic arch (Figure 1).

Consequently, 2 new classification systems have been developed to address dissections involving the aortic arch. The Society of Thoracic Surgery (STS) and Society of Vascular Surgery (SVS) classification system is based on aortic zones. ${ }^{3}$ TBAD is defined by an entry tear originating distal to the innominate artery (in or distal to aortic zone 1). The proximal and distal extent of the dissection is described by its aortic zones. The STS/SVS classification system is intended to facilitate data collection for research, allowing a detailed, standardized description of aortic disease. Although invaluable for examining study populations, this classification system is challenging to translate into clinical treatment options; the cardiovascular surgery community needs a user-friendly way of doing so (Figure 2).

The European Association for Cardio-Thoracic Surgery (EACTS) and European Society for Vascular Surgery system classify aortic dissection as type non-A-non-B when the aortic arch is affected. This class includes 2 different mechanisms of injury: an entry tear originating within the arch, and retrograde dissection. ${ }^{4}$ A separate classification for aortic arch involvement was created to reflect a significantly worse prognosis in cases involving injury to the arch than in dissections originating distal to the left subclavian. The proposed EACTS/European Society for Vascular Surgery classification system is simpler than the STS/SVS system and may be more user friendly for practicing cardiovascular surgeons (Figure 3).

Currently, neither of the 2 newer anatomic classification systems has been proven superior in aiding decision making regarding medical or endovascular intervention in acute cases. Therefore, further validation is needed from the cardiovascular community.

\section{Classification Based on Timing}

The STS/SVS and EACTS/European Society of Cardiology reporting standards and recommendations have updated definitions regarding the timing of aortic dissection:
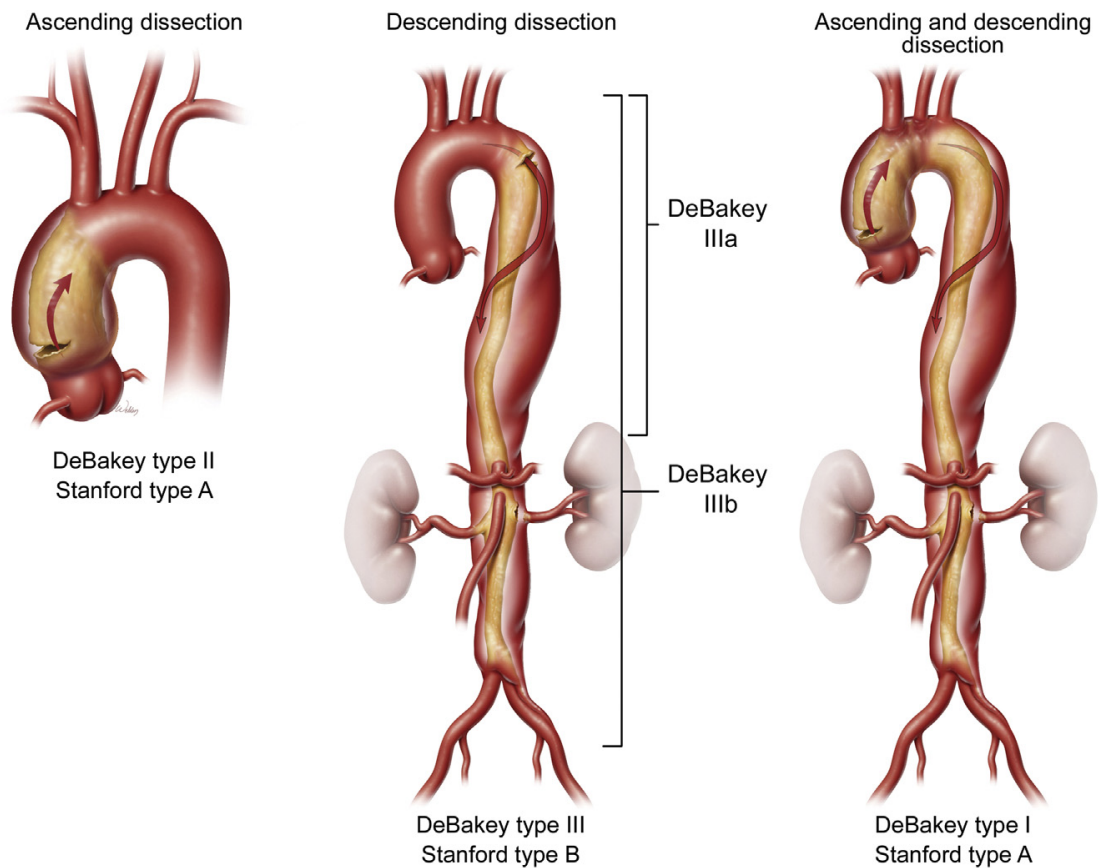

FIGURE 1. Stanford and DeBakey classifications of aortic dissection. Used with permission from Baylor College of Medicine. 


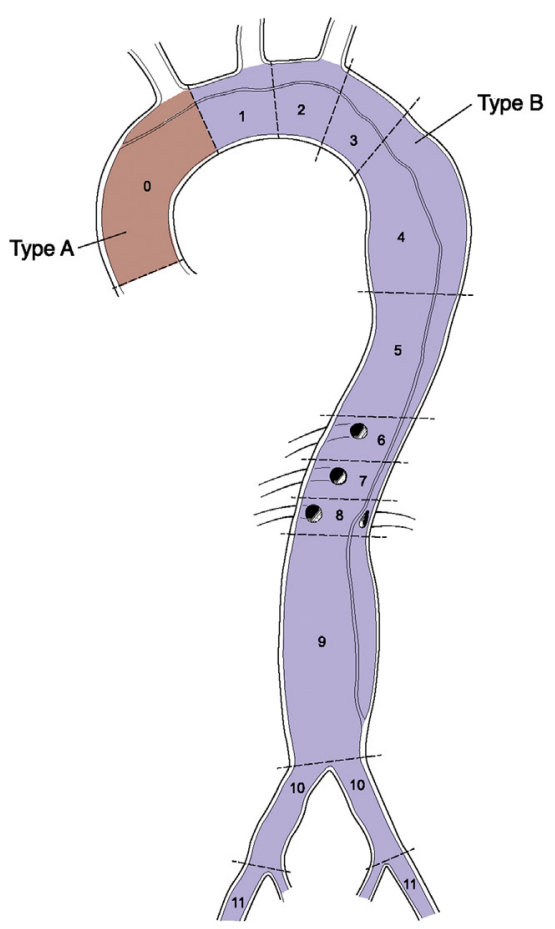

FIGURE 2. Society for Vascular Surgery/Society of Thoracic Surgeons Aortic Dissection Classification System of dissection subtype according to zone location of primary entry tear. ${ }^{3}$ Used with permission from The Society of Thoracic Surgeons.

hyperacute $<24$ hours, acute 1 to 14 days, subacute 15 to 90 days, and chronic $>90$ days. ${ }^{3,5}$ These proposed demarcations of chronicity reflect that mortality significantly decreases beyond 14 days. This change in classification is notable because it facilitates decision making regarding endovascular treatment given that the dissection flap is still compliant and amenable to thoracic endovascular aortic repair (TEVAR) within 90 days of the index event.

In addition to the abovementioned classification systems, 2 more classifications have been previously proposed. In 2012, Augoustides and colleagues ${ }^{6}$ proposed the Penn Classification system: 4 classes of clinical presentation based on the presence of branch-vessel malperfusion, circulatory compromise, or both. Dake and colleagues ${ }^{7}$ in 2013 proposed the DISSECT classification system, which is based on 6 characteristics that could influence therapeutic options: duration of disease, intimal tear location, size of the dissected aorta, segmental extent of aortic involvement, clinical complications of the dissection, and thrombus within the aortic false lumen. Since their introduction (2012 and 2013), neither of these classification systems has been widely adopted.

\section{Presence of Complications}

Two life-threatening complications that arise from acute TBAD are rupture and malperfusion. ${ }^{8}$ Rupture with extravasation outside the adventitia of the aorta manifests as a hemothorax or a periaortic or mediastinal hematoma. ${ }^{3}$
Malperfusion is the most common indication for emergency intervention and is the result of inadequate blood flow to a tissue bed (cerebral, renal, visceral, iliofemoral, or spinal cord) ${ }^{8}$ It is further characterized by dynamic or static mechanisms. Dynamic malperfusion occurs when, during the cardiac cycle, changes in blood flow and pressure between the true and false lumens cause intermittent obstruction of a branch vessel by the mobile dissection flap of the vessel's orifice. Dynamic mechanisms cause $80 \%$ of all malperfusion syndromes. ' Static malperfusion occurs when there is a fixed obstruction of the true lumen due to intussusception of the intimal flap into the branch vessel, dissection extending into the branch vessel with narrowing or thrombosis, or continuous pressurization of the false lumen throughout the cardiac cycle. In many cases, both dynamic and static mechanisms are present.

The mechanism of malperfusion can be difficult to identify on computed tomographic angiography (CTA). Realtime studies without radiation exposure or contrast, such as intravascular ultrasonography, allow evaluation of septal dynamics and flow during the cardiac cycle. Approximately $25 \%$ to $40 \%$ of acute TBAD cases are complicated by malperfusion or hemodynamic instability. ${ }^{10}$ In addition to rupture and malperfusion, other high-risk features of TBAD have been reported: refractory pain, refractory hypertension, bloody pleural effusion, aortic diameter $>40 \mathrm{~mm}$, readmission, malperfusion with only radiologic evidence, entry tear on the lesser curvature of the arch, and aortic false lumen diameter $>22 \mathrm{~mm}^{3}$

\section{TREATMENT STRATEGIES AND INDICATIONS FOR REPAIR IN ACUTE TYPE B AORTIC DISSECTION \\ Medical Management}

The cornerstones of medical therapy for acute TBAD are anti-impulse therapy and pain control. ${ }^{11}$ According to the International Registry of Acute Aortic Dissection, over a 17-year period, the majority of patients were treated medically. ${ }^{12}$ In addition, the International Registry of Acute Aortic Dissection data showed that the use of beta blockers was associated with better outcomes in all patients who presented with dissection (acute type A and acute type B), and the use of calcium channel blockers was associated with longer survival in all patients with acute TBAD, including the ones treated medically. ${ }^{13}$ We prefer to administer esmolol, labetalol, or nicardipine. Other medications such as nitroprusside (a vasodilator) and clevidipine (a calcium channel blocker) have been also used. ${ }^{14}$ Our hemodynamic targets are a heart rate of $<70$ beats per minute and systolic blood pressure between 100 and $120 \mathrm{~mm} \mathrm{Hg}$. Refractory hypertension, as well as the need for systolic blood pressure $>120 \mathrm{~mm} \mathrm{Hg}$ for adequate vital organ perfusion in patients with severe chronic hypertension, usually prompts us to proceed with surgical intervention. 


\section{Surgical Intervention}

There are important benefits of endovascular repair in acute cases. The objectives of TEVAR in patients with acute TBAD are to cover the primary entry tear, redirect flow to the true lumen, depressurize the false lumen, and resolve any malperfusion. The long-term objectives of TEVAR are remodeling of the dissected aorta, thrombosis of the false lumen, and avoiding future open or endovascular interventions. Various studies show a mortality, paraplegia, and stroke benefit for TEVAR versus open surgical repair. ${ }^{15-18}$ In patients with connective tissue disorders and malperfusion, endovascular repair is the first-line therapy; it can be a temporizing strategy for eventual open surgical repair. ${ }^{19}$ Open surgical repair is reserved for situations in which hostile anatomy makes endovascular repair technically infeasible. ${ }^{18,20,21}$

\section{Indications for and Timing of Intervention}

The standard treatment approach for acute complicated TBAD, defined as impending rupture or clinical malperfusion, is to reduce morbidity and mortality risk with endovascular therapy. Complicated TBAD has an early mortality rate of $16 \%$ and a 5 -year mortality of $40 \% .^{20,22}$ Endovascular therapy resulted in a $6.8 \%$ operative mortality rate, $6.8 \%$ stroke rate, $5.5 \%$ paraplegia/paraparesis rate, $6.8 \%$ rate of renal failure requiring dialysis, and $1.4 \%$ bowel ischemia rate in a prospective, nonrandomized single-arm, multicenter study examining acute complicated TBADs (Use of the Zenith Dissection Endovascular System in the Treatment of Patients With Acute, Complicated Type B Aortic Dissection [STABLE II]). ${ }^{23}$ At 1 year, there was favorable remodeling; almost all patients had partial or complete false lumen thrombosis.

In our opinion, the term uncomplicated acute aortic dissection, which is often used in the literature, is misleading and unsuitable given the natural history and late complications of the disease. As a result, there is controversy regarding the need for and timing of intervention in patients with no clinical malperfusion or impending rupture. We do know that $60 \%$ of patients with acute uncomplicated TBAD have aneurysmal rupture or dilatation requiring surgical repair within 5 years of initial presentation, ${ }^{24-27}$ and that $25 \%$ to $30 \%$ of uncomplicated acute TBAD cases progress to a complicated state. ${ }^{28}$ Although the practice is not universal, there is a trend ${ }^{29}$ toward using TEVAR to treat patients with uncomplicated acute TBAD but with substantial features and radiologic evidence of malperfusion. This is our preferred approach, as well. Nevertheless, it is important for us as surgeons to be specific and justify why and when we are to intervene in these patients.

The 2-year Investigation of Stent Grafts in Aortic Dissection randomized trial and the 5-year Investigation of Stent
Grafts in Aortic Dissection XL trial, which were performed in patients with subacute to chronic dissection (2-52 weeks) and not patients in the hyperacute or acute phase, medical and endovascular therapy together were associated with better 5-year aorta-specific survival and delayed progression of the disease than medical therapy alone. ${ }^{15}$ The European aortic guidelines recommend that TEVAR be considered in uncomplicated TBAD (Class IIA, level of evidence: B). ${ }^{5}$ Regarding the timing of intervention, the Valiant Thoracic Stent Graft Evaluation for Treatment of Descending Thoracic Aortic Dissections registry found similar aortic remodeling between the acute phase ( $<15$ days) and subacute phase (15-92 days) with less aortic remodeling in the chronic phase ( $>92$ days). ${ }^{30}$ There were 2 instances of retrograde type A aortic dissection in the acute phase. Five-year data from 50 patients who were treated for acute complicated TBAD with the Valiant thoracic stent graft and the Captivia delivery system (Medtronic Inc, Santa Rosa, Calif) in a prospective nonrandomized dissection trial, ${ }^{31}$ freedom from dissection-related mortality was $83 \%$, and freedom from secondary procedures related to dissection was $86 \%$. Positive aortic remodeling with a stable or decreased false lumen was seen in $77 \%$ of patients, and true-lumen diameter over the length of the stent graft increased or remained stable in $94 \%$. Desai and colleagues $^{32}$ found that TEVAR had fewer complications when performed in the subacute phase ( $<42$ days) than in the acute phase ( $<14$ days). In particular, retrograde type A dissection was more common in the acute phase, and the authors and others have suggested that treatment during the subacute phase is optimal. ${ }^{32,33}$ We want to emphasize that the knowledge of wire and catheters and the skill set that is required to treat patients with aortic dissection is key for any interventionalist performing TEVAR to avoid periprocedural complications.

The Acute Dissection: Stent Graft or Best Medical Therapy trial was a randomized trial of TEVAR versus optimal therapy in 61 patients with uncomplicated acute TBAD. ${ }^{34}$ The TEVAR group had greater aortic remodeling with false lumen thrombosis and reduction of false lumen diameter. ${ }^{34}$ Qin and colleagues ${ }^{35}$ compared TEVAR and optimal medical therapy in a retrospective study of 338 patients with uncomplicated TBAD. The TEVAR group had fewer aorticrelated adverse events, including rupture, aortic enlargement $(>60 \mathrm{~mm})$, retrograde type A aortic dissection, ulcer-like projection, endoleak, and stent graft-induced new entry $(24 \%$ vs $38 \%){ }^{35}$ The 5 -year survival rate was higher in the TEVAR group ( $89 \%$ vs $86 \%$ ). ${ }^{35}$ Furthermore, TEVAR had a favorable safety profile, being associated with a 30-day mortality rate of $0.5 \%$.

\section{Intraoperative Adjuncts and Devices}

Intravascular ultrasonography (IVUS) should be used to confirm the position of the stent graft inside the true lumen. 

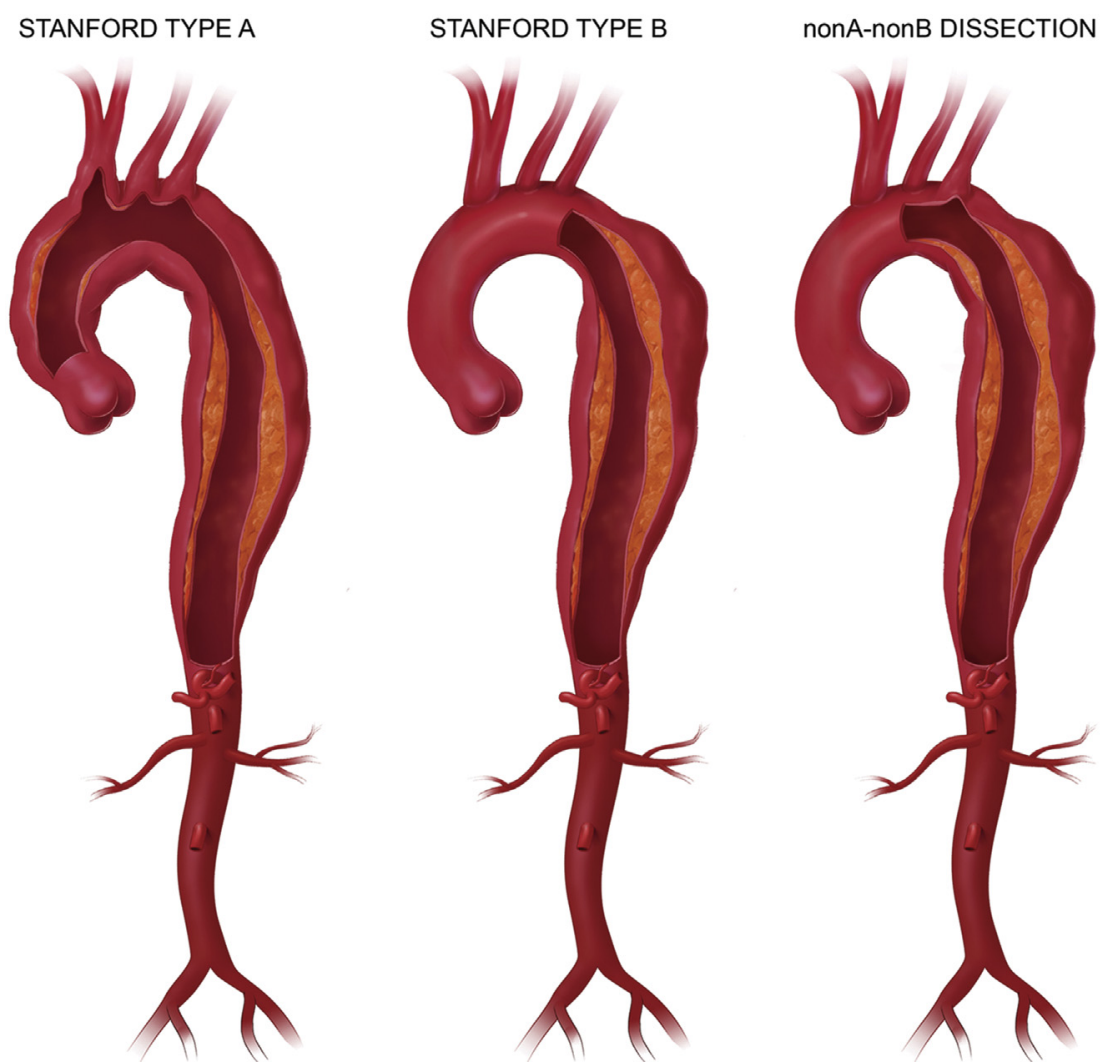

FIGURE 3. Definitions of aortic dissections. ${ }^{4}$ Used with permission of the European Association for Cardio-Thoracic Surgery.

IVUS can facilitate guidance of the wires and catheters into the true lumen instead of the false one, assess for dynamic or static malperfusion, and confirm the locations of the arch branch vessels and the visceral vessels. We have found that in acute TBAD complicated by visceral, renal, or lowerlimb malperfusion, coverage down to the celiac artery is usually necessary. Adjunctive branch-vessel stenting may be required. In patients with static malperfusion, if endovascular intervention does not achieve adequate revascularization, an extra-anatomical arterial reconstruction may be required. To reduce the risk of spinal cord ischemia associated with extensive coverage of descending thoracic aorta, a cerebrospinal fluid (CSF) drain can be inserted preoperatively unless the patient is receiving anticoagulant agents. Maintaining a higher-than-usual mean arterial pressure and avoiding hemodynamic instability may be among the most important steps, if not the most important, in avoiding spinal cord ischemia, not only in acute aortic dissection cases but also in all endografting in the descending thoracic aorta. ${ }^{36}$ During operations for acute TBAD, we maintain a mean arterial pressure of approximately 80 to $90 \mathrm{~mm} \mathrm{Hg}$ to ensure adequate spinal cord perfusion pressure.

As of this writing (ie, December 2020), the following devices have been approved for endovascular repair of acute TBAD by the Food and Drug Administration: the Zenith
Tx2/Alpha (Cook Medical, Inc, Bloomington, Ind), Navion/Valiant (Medtronic, Minneapolis, Minn), and TAG/ CTAG (W.L. Gore \& Associated, Inc, Flagstaff, Ariz). The diameter of the endograft should be $<10 \%$ oversized to the proximal and distal landing zones according to centerline measurements from the CTA, or not oversized at all. The diameter and cross-sectional areas are corroborated on IVUS or are obtained from preoperative CT imaging. Although coverage of the primary tear is important, it is our preference to cover the descending thoracic aorta up to the level of, or few centimeters above, the celiac axis.

The Provisional Extension to Induce Complete Attachment (PETTICOAT) is an endovascular concept that translates to covering the descending thoracic aorta with an endograft and covering the visceral vessels with baremetal stents to allow flow into the visceral vessels while promoting remodeling of the true lumen of the thoracoabdominal aorta. ${ }^{37-39}$ The PETTICOAT technique is particularly useful in cases of malperfusion, and evidence supports a wider application to all cases of acute TBAD to induce better aortic remodeling. ${ }^{37-39}$ Others have advocated for the Stent-Assisted Balloon-Induced Intimal Disruption and Relamination in Aortic Dissection Repair technique, which includes proximal exclusion, extension with bare-metal stents, and disrupting the septum with a 
balloon in the lower descending aorta to achieve a better apposition of the intima. ${ }^{40-42}$

Among the most serious complications during TEVAR for acute TBAD is retrograde type A aortic dissection. ${ }^{43}$ This complication has a reported $3.6 \%$ incidence when TEVAR is performed in acute dissection cases and up to $8.3 \%$ when it is performed in patients with a connective tissue disorder. ${ }^{43,44}$ Diameter of the ascending aorta $>4 \mathrm{~cm}$ may be associated with retrograde type A aortic dissection, but wire manipulation might be the most important risk factor for this dreaded complication. ${ }^{45,46}$ Arch-branched devices are currently under investigation and may be helpful to address acute aortic dissection with aortic arch involvement. ${ }^{47,48}$

\section{Our Approach}

Choice and timing of intervention for TBAD. Based on our experience, and on our thought process that there is no such entity as uncomplicated TBAD, our algorithm starts always with medical treatment and pain control as previously described. In addition, in patients with impending rupture, clinical or radiologic malperfusion, or bloody pleural effusion, we proceed with emergency TEVAR upon presentation. If any of the other high-risk features are present such as refractory pain, refractory hypertension, a false-lumen diameter $>2.2 \mathrm{~mm}$, an aortic diameter $>4 \mathrm{~cm}$, and entry tear in the lesser curvature of the aortic arch, then we proceed with TEVAR during the same hospital admission. Our belief regarding timing in these settings is distancing the TEVAR from the hyperacute and the early acute phase, instead performing TEVAR closer to the late acute phase or the subacute phase of the aortic dissection, especially in patients with dilated ascending aorta.

Intraoperative tips. We use IVUS as described above, and we prefer to cover with the stent graft most of the descending thoracic aorta. We avoid ballooning in acute cases (and we will continue to avoid it until more evidence shows that disrupting the septum is beneficial in such cases), and we do not oversize the graft by more than $10 \%$. We have used all the approved stent grafts, and in cases with malperfusion, we favor the PETTICOAT technique: realigning the true lumen of the lower descending thoracic aorta and the remaining abdominal aorta with uncovered stents. In our experience, this usually resolves the malperfusion. Visceral endovascular stenting or iliac stenting occasionally is required if the malperfusion persists despite the TEVAR. This, too, usually resolves the malperfusion.

Postoperative tips. Postoperative care is very important in these patients. We maintain a mean arterial pressure of approximately 80 to $90 \mathrm{~mm} \mathrm{Hg}$ to ensure adequate spinal cord perfusion pressure. These patients undergo frequent neurologic checks (every hour) within the first 24 hours. We keep the CSF drain in place for approximately 24 to
48 hours postoperatively in these patients if we have concerns about spinal cord perfusion, and the CSF pressure is kept at $<15 \mathrm{~mm} \mathrm{Hg}$. We strongly believe that the most important adjunct for spinal cord protection is avoiding hemodynamic instability and maintaining a higher perfusion pressure. If the CSF drain was not placed preoperatively and a patient awakens with neurologic deficit, then we immediately raise the blood pressure to a mean of approximately $100 \mathrm{~mm} \mathrm{Hg}$, administer steroids ( $10 \mathrm{mg}$ intravenous dexamethasone every 12 hours for 48 hours), administer mannitol (12.5 g intravenous every 12 hours for 48 hours), and place a CSF drain. The CSF pressure is kept at $12 \mathrm{~mm}$ $\mathrm{Hg}$. Our postoperative protocol to manage spinal cord deficit is the same for both TEVAR for descending thoracic pathology and open repair of a thoracoabdominal aneurysm. ${ }^{49}$ Having a protocol in place is important so that the entire team, including the bedside nurses, are aware of the plan of action.

Surveillance. TBAD is a lifelong illness that requires ongoing anti-impulse therapy to minimize aortic wall shear stress and serial imaging to monitor for endograft complications, redissection, and aneurysmal formation. Aortic growth occurs in $40 \%$ of patients after TEVAR, and secondary interventions are needed in more than $30 \% .{ }^{29,50}$ Our routine surveillance schedule calls for cross-sectional imaging before the patient's discharge, again in 3 to 6 months, then annually. In patients with compromised kidney function, instead of imaging in-hospital before discharge, imaging is requested 1 month after discharge, provided that the patient's kidney function has improved, and then in 6 months and 1 year. Noncontrast magnetic resonance angiography is an alternative for patients with impaired renal function. Magnetic resonance angiography also can be useful in limiting radiation exposure for younger patients.

\section{CONCLUSIONS}

Patients with acute TBAD require prompt medical management to control pain and blood pressure. Increasing evidence suggests that TEVAR induces favorable aortic remodeling. In patients who have acute TBAD complicated by rupture or malperfusion, endovascular therapy is the first line of treatment. In patients with high-risk clinical or radiographic features, there is increasing evidence that TEVAR is beneficial even though its use under these circumstances can be controversial. The procedure-related risk is low when TEVAR is performed at experienced aortic centers and by experienced surgeons. Open repair is reserved for situations in which endovascular repair is technically not feasible.

\section{Conflict of Interest Statement}

The authors reported no conflicts of interest. 
The Journal policy requires editors and reviewers to disclose conflicts of interest and to decline handling or reviewing manuscripts for which they may have a conflict of interest. The editors and reviewers of this article have no conflicts of interest.

\section{References}

1. Daily PO, Trueblood HW, Stinson EB, Wuerflein RD, Shumway NE. Management of acute aortic dissections. Ann Thorac Surg. 1970;10:237-47.

2. Debakey ME, Henly WS, Cooley DA, Morris GC Jr, Crawford ES, Beall AC Jr. Surgical management of dissecting aneurysms of the aorta. J Thorac Cardiovasc Surg. 1965;49:130-49.

3. Lombardi JV, Hughes GC, Appoo JJ, Bavaria JE, Beck AW, Cambria RP, et al. Society for Vascular Surgery (SVS) and Society of Thoracic Surgeons (STS) reporting standards for type B aortic dissections. Ann Thorac Surg. 2020;109:959-81.

4. Czerny M, Schmidli J, Adler S, van den Berg JC, Bertoglio L, Carrel T, et al. Current options and recommendations for the treatment of thoracic aortic pathologies involving the aortic arch: an expert consensus document of the European Association for Cardio-Thoracic Surgery (EACTS) and the European Society for Vascular Surgery (ESVS). Eur J Cardiothorac Surg. 2019;55:133-62.

5. Erbel R, Aboyans V, Boileau C, Bossone E, Bartolomeo RD, Eggebrecht H, et al. 2014 ESC guidelines on the diagnosis and treatment of aortic diseases: document covering acute and chronic aortic diseases of the thoracic and abdominal aorta of the adult. The Task Force for the Diagnosis and Treatment of Aortic Diseases of the European Society of Cardiology (ESC). Eur Heart J. 2014;35:2873-926.

6. Augoustides JG, Szeto WY, Woo EY, Andritsos M, Fairman RM, Bavaria JE. The complications of uncomplicated acute type-B dissection: the introduction of the Penn classification. J Cardiothorac Vasc Anesth. 2012;26:1139-44.

7. Dake MD, Thompson M, van Sambeek M, Vermassen F, Morales JP. DISSECT: a new mnemonic-based approach to the categorization of aortic dissection. Eur J Vasc Endovasc Surg. 2013;46:175-90.

8. Malaisrie SC, Mehta CK. Updates on indications for TEVAR in Type B aortic dissection. Innovations (Phila). 2020;15:495-501.

9. Crawford TC, Beaulieu RJ, Ehlert BA, Ratchford EV, Black JH III. Malperfusion syndromes in aortic dissections. Vasc Med. 2016;21:264-73.

10. Fattori R, Montgomery D, Lovato L, Kische S, Di Eusanio M, Ince H, et al. Survival after endovascular therapy in patients with type B aortic dissection: a report from the International Registry of Acute Aortic Dissection (IRAD). JACC Cardiovasc Interv. 2013;6:876-82.

11. Hiratzka LF, Bakris GL, Beckman JA, Bersin RM, Carr VF, Casey DE Jr, et al. 2010 ACCF/AHA/AATS/ACR/ASA/SCA/SCAI/SIR/STS/SVM guidelines for the diagnosis and management of patients with thoracic aortic disease. A report of the American College of Cardiology Foundation/American Heart Association Task Force on Practice Guidelines, American Association for Thoracic Surgery, American College of Radiology, American Stroke Association, Society of Cardiovascular Anesthesiologists, Society for Cardiovascular Angiography and Interventions, Society of Interventional Radiology, Society of Thoracic Surgeons, and Society for Vascular Medicine. J Am Coll Cardiol. 2010;55: e27-129.

12. Pape LA, Awais M, Woznicki EM, Suzuki T, Trimarchi S, Evangelista A, et al. Presentation, diagnosis, and outcomes of acute aortic dissection: 17-year trends from the International Registry of Acute Aortic Dissection. J Am Coll Cardiol. 2015;66:350-8.

13. Suzuki T, Isselbacher EM, Nienaber CA, Pyeritz RE, Eagle KA, Tsai TT, et al. Type-selective benefits of medications in treatment of acute aortic dissection (from the International Registry of Acute Aortic Dissection [IRAD]). Am J Cardiol. 2012;109:122-7.

14. Alviar CL, Gutierrez A, Cho L, Krishnaswamy A, Saleh A, Lincoff MA, et al. Clevidipine as a therapeutic and cost-effective alternative to sodium nitroprusside in patients with acute aortic syndromes. Eur Heart J Acute Cardiovasc Care. 2020;9:S5-12.

15. Nienaber CA, Kische S, Rousseau H, Eggebrecht H, Rehders TC, Kundt G, et al. Endovascular repair of type B aortic dissection: long-term results of the randomized investigation of stent grafts in aortic dissection trial. Circ Cardiovasc Interv. 2013;6:407-16.

16. Moulakakis KG, Mylonas SN, Dalainas I, Kakisis J, Kotsis T, Liapis CD. Management of complicated and uncomplicated acute type B dissection. A systematic review and meta-analysis. Ann Cardiothorac Surg. 2014;3:234-46.
17. Eggebrecht $H$, Nienaber $C A$, Neuhäuser $M$, Baumgart $D$, Kische $S$, Schmermund A, et al. Endovascular stent-graft placement in aortic dissection: a meta-analysis. Eur Heart J. 2006;27:489-98.

18. Fattori R, Tsai TT, Myrmel T, Evangelista A, Cooper JV, Trimarchi S, et al. Complicated acute type B dissection: Is surgery still the best option? A report from the International Registry of Acute Aortic Dissection. JACC Cardiovasc Interv. 2008;1:395-402.

19. Preventza O, Mohammed S, Cheong BY, Gonzalez L, Ouzounian M, Livesay JJ, et al. Endovascular therapy in patients with genetically triggered thoracic aortic disease: applications and short- and mid-term outcomes. Eur J Cardiothorac Surg. 2014; 46:248-53.

20. Afifi RO, Sandhu HK, Leake SS, Boutrous ML, Kumar V III, Azizzadeh A, et al. Outcomes of patients with acute Type B (DeBakey III) aortic dissection: a 13year, single-center experience. Circulation. 2015;132:748-54.

21. Appoo JJ, Bozinovski J, Chu MW, El-Hamamsy I, Forbes TL, Moon M, et al. Canadian Cardiovascular Society/Canadian Society of Cardiac Surgeons/Canadian Society for Vascular Surgery joint position statement on open and endovascular surgery for thoracic aortic disease. Can J Cardiol. 2016;32:703-13.

22. Ehrlich MP, Rousseau H, Heijmen R, Piquet P, Beregi JP, Nienaber CA, et al. Midterm results after endovascular treatment of acute, complicated type B aortic dissection: the Talent Thoracic Registry. J Thorac Cardiovasc Surg. 2013;145: 159-65.

23. Lombardi JV, Gleason TG, Panneton JM, Starnes BW, Dake MD, Haulon S, et al. STABLE II clinical trial on endovascular treatment of acute, complicated type B aortic dissection with a composite device design. J Vasc Surg. 2020;71: 1077-87.e2.

24. Juvonen T, Ergin MA, Galla JD, Lansman SL, McCullough JN, Nguyen K, et al. Risk factors for rupture of chronic type B dissections. J Thorac Cardiovasc Surg. 1999; 117:776-86.

25. Schwartz SI, Durham C, Clouse WD, Patel VI, Lancaster RT, Cambria RP, et al. Predictors of late aortic intervention in patients with medically treated type B aortic dissection. J Vasc Surg. 2018;67:78-84.

26. Durham CA, Cambria RP, Wang LJ, Ergul EA, Aranson NJ, Patel VI, et al. The natural history of medically managed acute type B aortic dissection. J Vasc Surg. 2015;61:1192-8.

27. Tsai TT, Fattori R, Trimarchi S, Isselbacher E, Myrmel T, Evangelista A, et al. Long-term survival in patients presenting with type B acute aortic dissection: insights from the International Registry of Acute Aortic Dissection. Circulation. 2006;114:2226-31.

28. Reutersberg B, Trenner M, Haller B, Geisbüsch S, Reeps C, Eckstein HH. The incidence of delayed complications in acute type B aortic dissections is underestimated. J Vasc Surg. 2018;68:356-63.

29. Tadros RO, Tang GHL, Barnes HJ, Mousavi I, Kovacic JC, Faries P, et al. Optimal treatment of uncomplicated type B aortic dissection: JACC review topic of the week. J Am Coll Cardiol. 2019;74:1494-504.

30. VIRTUE Registry Investigators. Mid-term outcomes and aortic remodelling after thoracic endovascular repair for acute, subacute, and chronic aortic dissection: the VIRTUE Registry. Eur J Vasc Endovasc Surg. 2014;48:363-71.

31. Bavaria JE, Brinkman WT, Hughes GC, Shah AS, Charlton-Ouw KM, Azizzadeh A, et al. Five-year outcomes of endovascular repair of complicated acute type B aortic dissections. J Thorac Cardiovasc Surg. May 13, 2020 [Epub ahead of print].

32. Desai ND, Gottret JP, Szeto WY, McCarthy F, Moeller P, Menon R, et al. Impact of timing on major complications after thoracic endovascular aortic repair for acute type B aortic dissection. J Thorac Cardiovasc Surg. 2015;149: S151-6.

33. Clough RE, Nienaber CA. Evidence for and risks of endovascular treatment of asymptomatic acute type B aortic dissection. J Cardiovasc Surg (Torino). 2017;58:270-7.

34. Brunkwall J, Kasprzak P, Verhoeven E, Heijmen R, Taylor P, Alric P, et al. Endovascular repair of acute uncomplicated aortic type B dissection promotes aortic remodelling: 1 year results of the ADSORB trial. Eur J Vasc Endovasc Surg. 2014;48:285-91.

35. Qin YL, Wang F, Li TX, Ding W, Deng G, Xie B, et al. Endovascular repair compared with medical management of patients with uncomplicated Type B acute aortic dissection. J Am Coll Cardiol. 2016;67:2835-42.

36. Preventza O, Wheatley GH III, Williams J, Ramaiah V, Rodriguez-Lopez J, Diethrich EB. Identifying paraplegia risk associated with thoracic endografting. Asian Cardiovasc Thorac Ann. 2009;17:568-72.

37. Nienaber CA, Kische S, Zeller T, Rehders TC, Schneider H, Lorenzen B, et al. Provisional extension to induce complete attachment after stent-graft placement 
in type B aortic dissection: the PETTICOAT concept. J Endovasc Ther. 2006;13: $738-46$.

38. Lombardi JV, Cambria RP, Nienaber CA, Chiesa R, Mossop P, Haulon S, et al. Aortic remodeling after endovascular treatment of complicated type B aortic dissection with the use of a composite device design. J Vasc Surg. 2014;59: $1544-54$.

39. Sultan I, Dufendach K, Kilic A, Bianco V, Trivedi D, Althouse AD, et al. Bare metal stent use in Type B aortic dissection may offer positive remodeling for the distal aorta. Ann Thorac Surg. 2018;106:1364-70.

40. Hofferberth SC, Nixon IK, Boston RC, McLachlan CS, Mossop PJ. Stent-assisted balloon-induced intimal disruption and relamination in aortic dissection repair: the STABILISE concept. J Thorac Cardiovasc Surg. 2014;147:1240-5.

41. Melissano G, Bertoglio L, Rinaldi E, Mascia D, Kahlberg A, Loschi D, et al. Satisfactory short-term outcomes of the STABILISE technique for type B aortic dissection. J Vasc Surg. 2018;68:966-75.

42. Faure EM, El Batti S, Sutter W, Bel A, Julia P, Achouh P, et al. Stent-assisted balloon-induced intimal disruption and relamination of distal remaining aortic dissection after acute DeBakey type I repair. J Thorac Cardiovasc Surg. 2019; 157:2159-65.

43. Chen Y, Zhang S, Liu L, Lu Q, Zhang T, Jing Z. Retrograde type A aortic dissection after thoracic endovascular aortic repair: a systematic review and meta-analysis. J Am Heart Assoc. 2017;6:e004649.

44. Eggebrecht H, Thompson M, Rousseau H, Czerny M, Lonn L, Mehta RH, et al. Retrograde ascending aortic dissection during or after thoracic aortic stent graft placement: insight from the European Registry on Endovascular Aortic Repair Complications. Circulation. 2009;120:S276-81.
45. Kpodonu J, Preventza O, Ramaiah VG, Shennib H, Wheatley GH III, Rodriquez Lopez J, et al. Retrograde type A dissection after endovascular stenting of the descending thoracic aorta. Is the risk real? Eur J Cardiothorac Surg. 2008;33:1014-8.

46. Preventza O, Garcia A, Moeller K, Cooley DA, Gonzalez L, Cheong BY, et al. Retrograde ascending aortic dissection after thoracic endovascular aortic repair for distal aortic dissection or with Zone 0 landing: association, risk factors, and true incidence. Ann Thorac Surg. 2015;100:509-15.

47. Patel HJ, Dake MD, Bavaria JE, Singh MJ, Filinger M, Fischbein MP, et al Branched endovascular therapy of the distal aortic arch: Preliminary results of the feasibility multicenter trial of the Gore thoracic branch endoprosthesis. Ann Thorac Surg. 2016;102:1190-8.

48. Ferrer C, Coscarella C, Cao P. Endovascular repair of aortic arch disease with double inner branched thoracic stent graft: the Bolton perspective. J Cardiovasc Surg (Torino). 2018;59:547-53.

49. Chatterjee S, Casar JG, LeMaire SA, Preventza O, Coselli JS. Perioperative care after thoracoabdominal aortic aneurysm repair: the Baylor College of Medicine experience. Part 2: postoperative management. J Thorac Cardiovasc Surg. 2021; 161:699-705.

50. Faure EM, Canaud L, Agostini C, Shaub R, Böge G, Marty-ané C, et al. Reintervention after thoracic endovascular aortic repair of complicated aortic dissection. J Vasc Surg. 2014;59:327-33.

Key Words: aortic dissection, acute type B aortic dissection, endovascular, medical therapy 